Case report

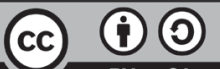

\title{
POROKERATOSIS PALMARIS, PLANTARIS, ET DISSEMINATA IN A PATIENT WITH VITILIGO AND RHEUMATOID ARTHRITIS
}

\author{
Stoyan I. Pavlov \\ Clinic of Dermatology and Venereology, University hospital St. Marina - Varna, \\ Bulgaria.
}

\begin{abstract}
Porokeratosis is a clonal disorder of the keratinization of the epidermis, manifested by atrophic papules or patches, surrounded by the hyperkeratotic ridge-like border, that corresponds to cornoid lamella histologically. We reported an association of a rare form of that distinctive disease - Porokeratosis Palmaris et plantaris disseminate with vitiligo in a 62-year-old female with rheumatoid arthritis on immunosuppressant treatment.
\end{abstract} thritis,

Keywords: porokeratosis, vitiligo, rheumatoid ar-

\section{INTRODUCTION}

Described by Vittorio Mibelli in 1893, porokeratosis currently accomplished at least six clinical forms: Dissminated superficial actinic porokeratosis (DSAP); Linear porokeratosis (LP); Porokeratosis of Mibelli (PM); Punctate porokeratosis (PP); Porokeratosis palmaris et plantaris disseminata (PPPD) and Disseminated superficial porokeratosis (DSP). [1] These six types, as well as the other more rare forms of porokeratosis, like dorokeratosis ptychotropica, facial porokeratosis, giant porokeratosis, hypertrophic verrucous porokeratosis, reticulate porokeratosis and eruptive pruritic papular porokeratosis, have a common histologic feature, called cornoid lamella, a column of parakeratotic cells, that corresponds to the elevated circumference of the porokeratosis lesion. [2] There is a $7 \%$ to $10 \%$ risk of malignant transformation usually into squamous cell carcinoma, Bowen's disease, and rarely, to basal cell carcinoma. $[1,3,4]$

The described case, to the best of our knowledge, is the first report in the literature of an association of rare sporadic form of PPPD and two autoimmune diseases (vitiligo and rheumatoid arthritis). Thus, the role of immunity as a mediator of the development of the porokeratosis can be discussed.

\section{CASE DESCRIPTION}

A 62-year female with a history of vitiligo from adolescence is reported. Depigmented macular skin lesions initially appeared on the upper limbs (Fig. 1), then were distributed to the thorax, abdomen and face, which tend to recover spontaneously after few months but reappeared afterwards on the approximate skin regions. The disorder started more than 10 years ago, when multiple, clustered, dot-like depressions, encircled by the frame of desquamated epithelium appeared on the palms and the feet (Fig. 2). Two years ago, round keratotic papules of 0.5 to $1 \mathrm{~cm}$ in size, surrounded by the well-defined and slightly elevated peripheral rim arose on the skin of the trunk at the area of the neckline (Fig. 4), on the periumbilical abdomen (Fig. 3), as well as on the arms. Similar skin manifestations were not found in her relatives. Histopathology of the specimen biopsied from the hyperkeratotic lesion of patient's arm established acanthosis and hyperkeratosis with parakeratotic cornoid lamella in the epidermis, and focal mononuclear infiltrate and marked solar elastosis in the dermis. Therefore, the report is conclusive to porokeratosis (Fig. 5).

Fig. 1. Depigmented macular skin lesions.

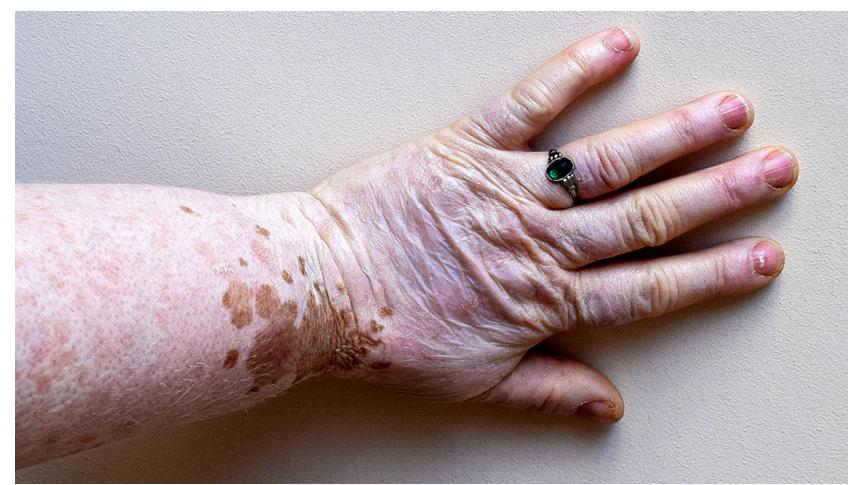


Fig. 2. Dot-like depressions, encircled by the frame of desquamated epithelium appeared on the palms.

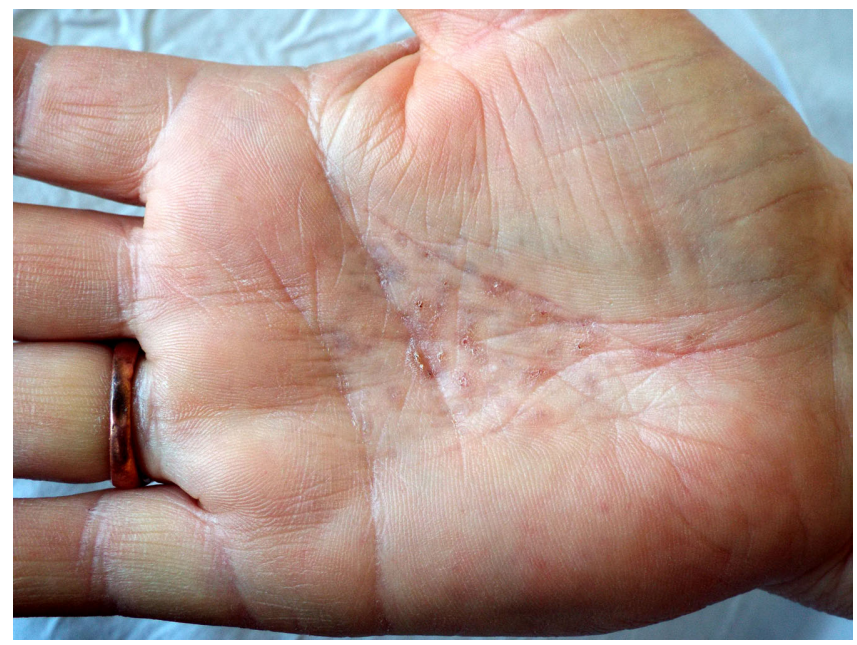

Fig. 3. Keratotic papules surrounded by slightly elevated peripheralrim.

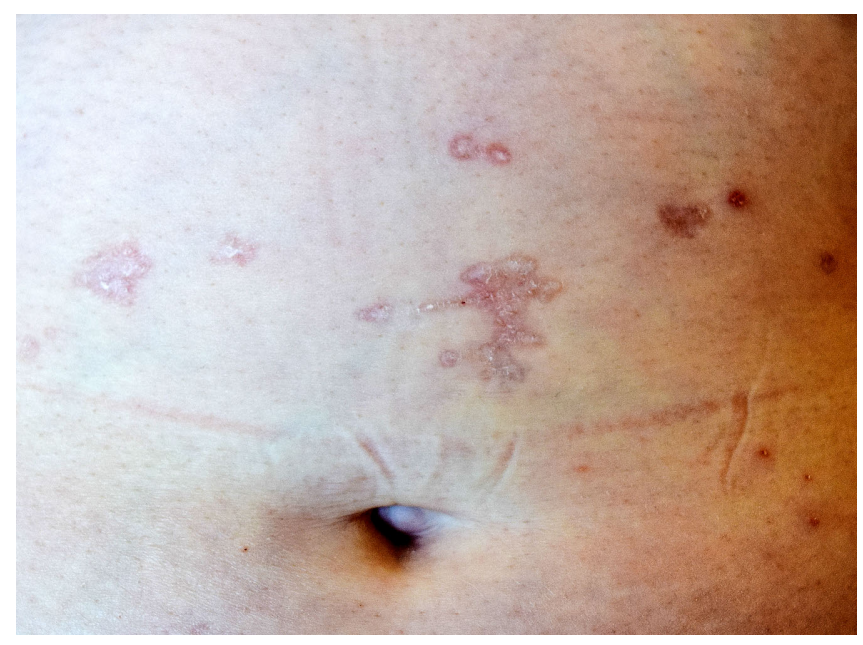

Fig. 4. Keratotic papulesat the area of the neckline.

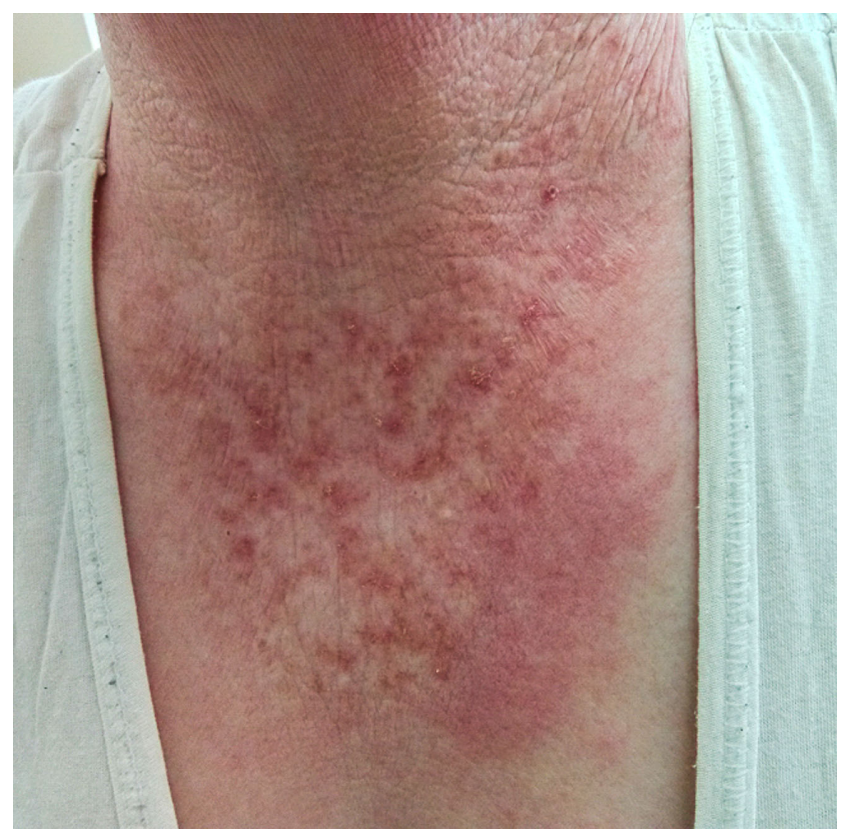

Fig. 5. Parakeratotic cornoid lamella in the epidermis, H\&Ex40.

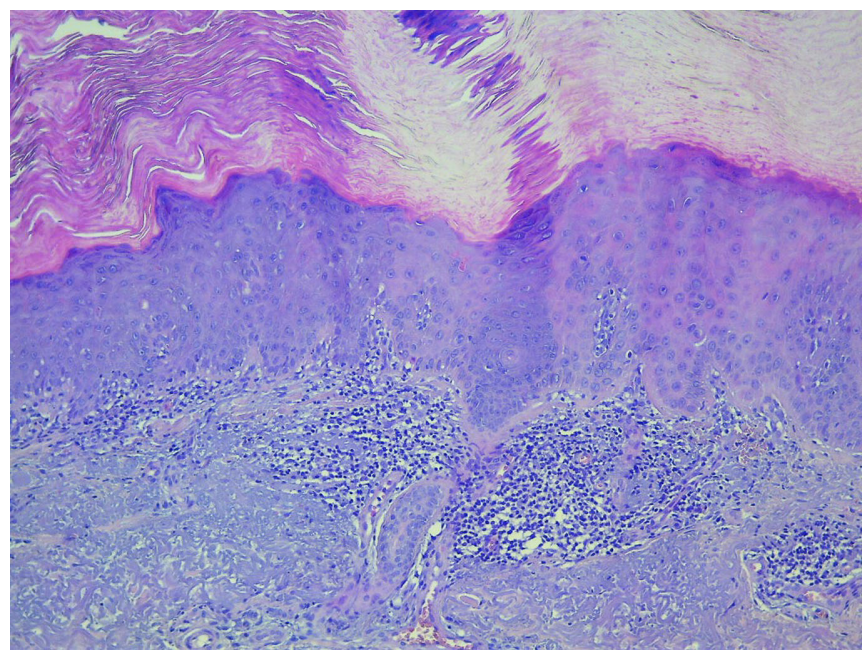

The patient's medical history is positive for seronegative Rheumatoid arthritis with multiple locations, IIstage with a 20-year duration and treatment with Methylprednisolone (mean dose of $8 \mathrm{mg}$ per day) and intermittent administration of Resochin $(250 \mathrm{mg}$, two times per day). The laboratory tests - blood count and biochemistry (AST, ALT, GGT, urea, creatinine and glucose) were normal. The microscopic investigation and the fungal culture were negative, as well as the serology for syphilis (VDRL and TPHA). The patient was referred for annual medical examinations by a dermatologist due to the available risk of malignant transformation of the lesions. In addition, photoprotection and cosmetic makeup were recommended for sun-exposed areas of the body affected by vitiligo.

\section{DISCUSSION}

In 1971, Stephen Guss described PPPD, as a distinctive form of the porokeratosis in 9 persons of 4 generations of the family, in which a consecutive involvement of the palms, feet and trunk was reported, including surfaces not exposed to ultraviolet radiation.[5] Afterwards, PPPD was assessed not only in patients with a familial, autosomal-dominant inheritance pattern but also as isolated cases, similar to our subject, probably due to a sporadic mutation. [6, 7]

Cause for development of the genetic defect in the keratinization, leading to the formation of the parakeratotic cells in the epidermis and the cornoid lamella is considered to be a mutagenic effect of the UV-light, that is manifested in the Disseminated superficial actinic porokeratosis (DSAP). Other predisposing factors are an immune suppression (in leukemia, human immunodeficiency virus infection, advanced liver diseases and organ transplantation), the pro-inflammatory state found in diabetes mellitus, Crohn disease, ulcerative colitis, dermatomyositis and rheumatoid arthritis and some medications. $[3,8]$

Similar to DSAP, characteristic for PPPD is the establishment of numerous disseminated lesions, but in 
contrast to DSAP, PPPD is not limited to sun-exposed areas, and the involvement of palms and feet is mandatory.[9-12]

Interestingly, in our reported case, part of the lesions was located strictly in the areas of solar insolation, like the neck, arms and shoulders at the same regions affecting by vitiligo. On the other hand, we found confluent porokeratosis lesions of the umbilical skin, that is never exposed to UV-radiation. Therefore, we can suggest that iatrogenic immunosuppression and pro-inflammatory cytokine status, related to the long-standing rheumatoid arthritis are predisposing factors for porokeratosis extension to the non-sun-exposed surfaces. The assessed in- volvement of porokeratosis outside the regions of vitiligo, where extensive actinic-induced degenerative processes are suggested, confirm the concept that other factors, such as genetic, inflammatory and drug-induced injury can cause porokeratosis. $[1,2]$

\section{CONCLUSION}

The reported clinical case is a manifestation of the rare PPPD, started on the skin of the thorax and the abdomen at the periumbilical region that is distributed in consequence to the palms, feet and to the extremities predominately in the areas, engaged by vitiligo.

\section{REFERENCES:}

1. Kanitakis J. Porokeratoses: An Update of Clinical, Aetiopathogenic and Therapeutic Features. Eur $J$ Dermatol. 2014 Sep-Oct;24(5):533-44. [PubMed] [Crossref]

2. Murase J, Gilliam AC. Disseminated superficial actinic porokeratosis co-existing with linear and verrucous porokeratosis in an elderly woman: Update on the genetics and clinical expression of porokeratosis. J Am Acad Dermatol. 2010 Nov;63(5):886-91. [PubMed] [Crossref]

3. Le C, Bedocs PM. Disseminated Superficial Actinic Porokeratosis. In: StatPearls [Internet]. Treasure Island (FL): StatPearls Publishing; 2020 Jan. [PubMed]

4. Jensen J-M, Egberts F, Proksch E, Hauschild A. Disseminated porokeratosis palmaris and plantaris treated with imiquimod cream to prevent ma- lignancy. Acta Derm Venereol. 2005; 85(6):550-1.[PubMed]

5. Guss SB, Osbourn RA, Lutzner MA. Porokeratosis Plantaris, Palmaris, et Disseminata. Arch Dermatol. 1971 Oct;104(4):366-373.[P PubMed] [Crossref]

6. Marschalko M, Somlai B. Porokeratosis plantaris, palmaris, et disseminata. Arch Dermatol. 1986 Aug; 122(8):890-1. [PubMed] [Crossref]

7. Sawheny MP, Mahatachar V, Bisht YS. Porokeratosis plantaris palmaris et disseminata. Indian J Dermatol Venereol Leprol. 1995Jan-Feb; 61(1):48-9. [PubMed]

8. Raychaudhuri SP, Smoller BR. Porokeratosis in immunosuppressed and nonimmunosuppressed patients. Int J Dermatol. 1992 Nov;31(11):7812. [PubMed] [Crossref]

9. Hartman R, Mandal R, Sanchez
M, Stein JA. Porokeratosis plantaris, palmaris, et disseminata. Dermatol Online J. 2010 Nov 15;16(11):22. [PubMed]

10. Udare S, Hemmady K. Clinical and dermatoscopic features of porokeratosis palmaris et plantaris. Indian Dermatol OnlineJ. 2016 Jul-Aug; 7(4):290-2.[PubMed]

11. Lanka P, Lanka LR, Manivachagam D. Punctate Porokeratosis Palmaris et Plantaris. Indian J Dermatol. 2015 May-Jun; 60(3):2846. [PubMed]

12. Veasey JV, Dalapicola MC, Lellis RF, Campaner AB, da Silveira Manzione T, de Faria Soares Rodrigues MS. Porokeratosis ptychotropica: a rare manifestation with typical histological exam. An Bras Dermatol. 2016 Jul-Aug;91(4):496-8. [PubMed] [Crossref $]$

Please cite this article as: Pavlov SI. Porokeratosis palmaris, plantaris, et disseminata in a patient with vitiligo and rheumatoid arthritis. J of IMAB. 2020 Jul-Sep;26(3):3285-3287. DOI: https://doi.org/10.5272/jimab.2020263.3285

Address for correspondence:

Stoyan Pavlov,

Clinic of dermatology and venereology, University hospital St. Marina- Varna, 1, Hristo Smirnenski Blvd., Varna, Bulgaria.

E-mail: stoyanpavlov@abv.bg, 